\title{
AFETOS DOCENTES E RELAÇÕES DE CUIDADO NA CRECHE: NARRATIVAS DE PROFESSORAS EM DISCUSSÃO
}

\author{
AFECTOS DOCENTES Y RELACIONES DE CUIDADO EN LA GUARDERÍA: \\ NARRATIVAS DE MAESTRAS EN DISCUSIÓN
}

\author{
AFFECTION IN TEACHING AND CARE RELATIONSHIPS IN NURSERY SCHOOLS: \\ NARRATIVES OF TEACHERS IN DISCUSSION
}

\author{
Rodrigo Saballa de CARVALHO ${ }^{1}$
}

RESUMO: O artigo apresenta resultados de uma pesquisa cujo foco analítico foi a problematização das concepções sobre afetos na docência no berçário. O mote de discussão da investigação foram os modos como as professoras significam as relações de afeto que permeiam as ações de cuidado desenvolvidas com as crianças. O campo teórico de fundamento da pesquisa foram os Estudos de Gênero, os Estudos da Pedagogia da Infância, assim como contribuições de pesquisas da antropologia e da sociologia que discutem a temática dos afetos. Metodologicamente, foi realizado um grupo focal com 20 professoras de bebês. Para tanto, foram propostos seis encontros, nos quais as professoras discutiram a temática do afeto e suas relações com a docência na Educação Infantil. A análise das narrativas docentes evidenciou a recorrência de duas concepções de afeto no exercício das ações de cuidado com os bebês: o afeto como imperativo; e o excesso de afeto como razão de desprestígio profissional. Embora o afeto seja entendido pelas professoras como um imperativo, é visto paralelamente como razão de desprestígio profissional quando demonstrado em excesso. Para as docentes, demonstrar afeto em excesso pelos bebês evidencia uma proximidade com a experiência materna, fato que gera a falta de reconhecimento profissional. Com base na pesquisa, concluiu-se que os significados dos afetos são construções culturais que demandam desnaturalização e reinvenção no âmbito da creche, tendo em vista a experimentação de modos próprios de exercício da docência.

PALAVRAS-CHAVE: Educação infantil. Creche. Docência. Cuidado. Afetos docentes.

RESUMEN: El artículo presenta resultados de una investigación cuyo enfoque analítico ha sido la problematización de las concepciones sobre afectos en la docencia en la guardería. El eje de discusión ha sido el modo como las maestras significan las relaciones de afecto que atraviesan las acciones de cuidado desarrolladas con niños. El campo teórico de fundamento ha sido los Estudios de Género, y de Pedagogía de la Infancia, así como contribuciones de investigaciones de la Antropología y de la Sociología que discuten la temática de los afectos. Metodológicamente, se ha realizado un grupo focal con 20 maestras de bebés. Se han

${ }^{1}$ Universidade Federal do Rio Grande do Sul (UFRGS), Porto Alegre - RS - Brasil. Professor do Programa de Pós-Graduação em Educação da na Linha de Pesquisa: Estudos sobre Infâncias. Professor da área de Educação Infantil do Departamento de Estudos Especializados (DEE) da Faculdade de Educação da UFRGS. Pós-Doutor em Educação (UFPEL). Doutor em Educação (UFRGS). Mestre em Educação (UFRGS). ORCID: <http://orcid.org/0000-0002-8899-0998>. E-mail: rsaballa@terra.com.br

RIAEE - Revista Ibero-Americana de Estudos em Educação, Araraquara, v. 14, n. 1, p. 188-207, jan./mar., 2019. E-ISSN: $1982-5587$. 
propuesto seis encuentros para discutir la temática del afecto y sus relaciones con la docencia en la Educación Infantil. El análisis de las narrativas docentes ha puesto de manifiesto la recurrencia de dos concepciones de afecto en el ejercicio de las acciones de cuidado con los bebés: el afecto como imperativo; y el exceso de afecto como motivo de desprestigio profesional. Aunque las maestras entiendan el afecto como un imperativo, se lo ven, paralelamente, como motivo de desprestigio profesional cuando se lo demuestran en exceso. Para las docentes, demostrar afecto en exceso por los bebés pone de manifiesto una proximidad con la experiencia materna, hecho que genera la falta de reconocimiento profesional. Se ha concluido que los significados de los afectos son construcciones culturales que demandan desnaturalización y reinvención en el marco de la guardería, teniendo en cuenta la experimentación de modos propios de ejercicio de la docencia.

PALABRAS-CLAVE: Educación infantil. Guardería. Docencia. Cuidado. Afectos docentes.

ABSTRACT: The paper presents results of a research whose analytical focus was the discussion of understandings of affection in teaching in nursery schools. The investigation's discussion focused on the ways in which teachers signify the relations of affection that permeate the actions of care developed with the children. The research's theoretical field was the Gender Studies, Early Childhood Pedagogy Studies, as well as research contributions from anthropology and sociology that discuss the theme of affection. Methodologically, a focus group was held with 20 infant teachers. For that, six meetings were proposed, in which the teachers discussed the theme of affection and its relationship with teaching in Early Childhood Education. The analysis of the teacher's narratives evidenced the recurrence of two understandings of affection in the exercise of actions of care with infants: affection as an imperative, and the excess of affection as a reason for professional discredit. Although affection is understood by teachers as an imperative, it is seen, in parallel, as a reason for professional discredit when demonstrated in excess. For teachers, showing excessive affection for infants indicates a proximity to the maternal experience, a fact that generates a lack of professional recognition. Based on the research, it was concluded that the meanings of affections are cultural constructions that demand denaturation and reinvention in nursery schools in order to experiment with their own modes of teaching.

KEYWORDS: Early childhood education. Nursery school. Teaching. Care. Affection in teaching.

\section{Introdução}

Os afetos docentes se referem especificamente aos "sentimentos que os professores evidenciam nas relações que estabelecem com as crianças, colegas e respectivas famílias atendidas" (ABRAMOWSKI, 2010, p. 23), durante a jornada diária de trabalho na instituição. Tais afetos estão adquirindo cada vez mais centralidade no âmbito da docência contemporânea na Educação Infantil, em especial no que diz respeito às práticas de cuidado com os bebês na creche. 
Dessa forma, nas pesquisas sobre formação docente (GONÇALVES, 2014; SCHMITT, 2014; CASTRO, 2016; CARVALHO; RADOWSKI, 2017), tem se considerado as relações decorrentes da atenção individualizada da professora com os bebês como uma das características específicas da ação pedagógica na creche. Isso equivale a afirmar que, entre as professoras atuando diariamente no berçário, é consenso que os bebês precisam de uma atenção profissional intensa, já que possuem necessidades "biológicas, físicas e emocionais que devem ser atendidas" (SCHMITT, 2014, p. 212). Nesse sentido, as relações sociais promotoras dos afetos docentes por meio das práticas de cuidado com os bebês na creche constituem espaços "de poder e resistência, por meio dos quais diferenças e éticas são comunicadas, negociadas e compartilhadas" (ABRAMOWSKI, 2010, p. 55).

Por todos esses aspectos indicados, é possível declarar que o afeto na docência com os bebês encontra-se diretamente vinculado a uma pedagogia das relações, na qual o cuidado, como ética, e a responsividade se configuram como referências para que seja pensada a ação pedagógica (CARVALHO; RADOMSKI, 2017). Isso porque os relacionamentos de cuidado, dentre os quais se incluem as práticas desenvolvidas na creche, "apresentam uma atenção pessoal contínua e intensa que melhora o bem-estar dos seus destinatários” (ZELIZER, 2011, p. 138).

Em tal perspectiva, a "creche enquanto unidade física e territorial é uma matriz relacional constitutiva de cuidados" (FERNANDES, 2011, p. 80) que opera como um espaço privilegiado na produção de afetos docentes (CARVALHO, 2014), "tributários das relações sociais, do contexto cultural" (REZENDE; COELHO, 2010, p. 11) e institucional do qual emergem. Os afetos docentes - destacando-se, no presente artigo, as relações decorrentes dos cuidados das professoras com os bebês - "não são naturais, espontâneos, instintivos, universais e nem imutáveis" (ABRAMOWSKI, 2010, p. 33), mas construídos, aprendidos e regulados no exercício diário da docência com bebês.

Partindo das considerações iniciais apresentadas, é importante esclarecer que este artigo é decorrente de uma pesquisa cujo foco analítico foi a problematização das concepções sobre afetos no exercício da docência no berçário. O fulcro de discussão do processo investigativo foram os modos como as professoras de berçário significam as relações de afeto que permeiam as ações de cuidado desenvolvidas diariamente com as crianças. Tratou-se, então, de discutir a dimensão ética do cuidado (GUIMARÃES, 2011), para além de uma ação instrumental sobre o corpo dos bebês. Assim, as práticas de cuidado foram entendidas, no desenvolvimento da pesquisa, como constituídas por afetos docentes (ABRAMOWSKI, 
2010), produtores de tensões e embates no contexto das relações de trabalho que as professoras de berçário estabelecem cotidianamente com suas colegas no interior da creche.

Para tanto, a pesquisa desenvolvida fundamentou-se nos Estudos de Gênero (TRONTO, 1997; LOURO, 1999; MEYER, 2003; STRATHERN, 2006), nos estudos do campo da Pedagogia da Infância sobre a docência com bebês (OSTETTO, 2008; GONÇALVES, 2014; GUIMARÃES, 2011; SCHMITT, 2014; MARTINS, 2014; CASTRO, 2016; CARVALHO; RADOMSKI, 2017), assim como em contribuições de pesquisas da antropologia e sociologia que discutem a temática dos afetos na cena contemporânea (ABRAMOWSKI, 2010; REZENDE; COELHO, 2010; ILLOUZ, 2011; ZELIZER, 2011; CARVALHO, 2014). Metodologicamente, o trabalho de campo foi desenvolvido a partir da proposição de um grupo focal ${ }^{2}$ (LEOVORLINO; PELICIONI, 2001; GONDIM, 2002; BARBOUR, 2009; FLICK, 2009) com 20 professoras de bebês de 6 a 14 meses. As professoras participantes da pesquisa tinham idades entre 25 e 35 anos, eram graduadas em Pedagogia e atuavam em turmas de berçário em creches públicas e privadas localizadas na região noroeste do estado do Rio Grande do Sul.

Para a operacionalização do trabalho de campo, foram realizados seis encontros, gravados em vídeo, com as professoras, mediados pelo coordenador da pesquisa e documentados por dois auxiliares, os quais atuaram como relatores das discussões desenvolvidas no grupo focal. Os encontros ocorreram duas vezes por semana, com sessões de uma hora de duração. A perspectiva cultural dos afetos docentes (ABRAMOWSKI, 2010; REZENDE; COELHO, 2010; CARVALHO, 2014) foi a temática central, permeando as discussões desenvolvidas em todos os encontros.

Na primeira reunião com as professoras, antes do início do trabalho de campo, foram expostos os objetivos, os procedimentos metodológicos previstos para o desenvolvimento da investigação e os aspectos éticos que seriam levados em consideração na divulgação das informações provenientes do grupo focal. Após as informações e esclarecimentos prestados, todas as professoras aceitaram participar da pesquisa, mediante a assinatura do Termo de Consentimento Livre e Esclarecido (TCLE).

Para a realização de cada um dos encontros, foi definido um plano de trabalho (GONDIM, 2002) constituído por um disparador de discussão e pelo debate promovido e moderado pelo coordenador da pesquisa. No entanto, considerando os limites do artigo, nas

${ }^{2} \mathrm{O}$ grupo focal, enquanto estratégia de investigação qualitativa, “[...] consiste na interação entre os participantes e o pesquisador, que objetiva colher dados a partir da discussão focada em tópicos específicos e diretivos" (LERVOLINO; PELICIONI, 2001, p. 116). 
análises a serem apresentadas, será focalizado o quarto encontro, no qual se discutiu com as professoras especificamente o tópico das relações (e tensões) entre afetos docentes e ações de cuidado com os bebês no contexto da creche.

Apresentadas essas primeiras considerações sobre o panorama da pesquisa e seus aspectos metodológicos, destaca-se que a análise das narrativas das professoras compartilhadas nas discussões do grupo focal evidenciou a recorrência de duas concepções de afeto no exercício das ações de cuidado com os bebês: o afeto como imperativo; e o (excesso de) afeto como razão de desprestígio profissional. Embora o afeto docente nas ações de cuidado com os bebês seja significado como um imperativo (CARVALHO, 2014), é visto, quando evidenciado em "excesso", como razão de desprestígio profissional, pelo fato de supostamente "descaracterizar" a ação pedagógica.

Para melhor compreensão do leitor, cabe informar que o artigo está organizado em quatro seções. A primeira, cujo título é "Afetos docentes e relações de cuidado: notas conceituais", apresenta os conceitos a partir dos quais serão operadas as análises das narrativas das professoras participantes da pesquisa. A segunda seção, intitulada "O afeto docente (como imperativo), o cuidado com os bebês e a regulação das emoções", e a terceira, nomeada “A 'correta medida' dos afetos nas relações de cuidado com os bebês", focalizam, respectivamente, as duas unidades analíticas que emergiram do exame do material empírico produzido durante a realização dos grupos focais. Por fim, a última seção do artigo apresenta as considerações finais.

\section{Afetos docentes e relações de cuidado: notas conceituais}

Os sentimentos não têm uma natureza universal, embora essa convicção ainda faça parte do senso comum ocidental (REZENDE; COELHO, 2010; ILLOUZ, 2011) e seja difusora de mandatos e estereótipos pedagógicos constituidores de uma "gramática das emoções"3 (REZENDE, 2012) no contexto das instituições educacionais. Em relação aos afetos, é possível afirmar que estes não possuem universalidade e tampouco singularidade, devendo, portanto, ser entendidos como elementos sociais. Os afetos fazem parte da dinâmica da vida das pessoas e, como tal, estão presentes no contexto de interações sociais específicas travadas no cotidiano.

3 Através do conceito de gramática das emoções, Rezende (2012, p. 831) destaca tanto a ideia de que "os sentimentos são culturalmente construídos, como também a visão de que há um conjunto de normas de expressão adequadas aos contextos distintos com os quais os indivíduos têm que lidar".

RIAEE - Revista Ibero-Americana de Estudos em Educação, Araraquara, v. 14, n. 1, p. 188-207, jan./mar., 2019. E-ISSN: 1982-5587. 
A palavra afeto deriva etimologicamente de "afecção", com o sentido de ser afetado, sofrer uma ação, ser influenciado ou ter o comportamento modificado por uma ação (CARVALHO, 2014). Como lembra Illouz (2011, p. 9), o "afeto não é uma ação em si, mas é a energia interna que impele o indivíduo a agir, que confere um 'clima' ou uma 'coloração' a um ato". Ou seja, o afeto, enquanto energia que movimenta as relações entre os indivíduos, implica, de forma simultânea, cognição, avaliação, motivação e corpo (ILLOUZ, 2011). Portanto, os afetos não são sentidos abstratamente, de modo independente das interações entre os indivíduos, nem à parte dos contextos dos quais emergem.

Nessa perspectiva, cabe reiterar que os afetos docentes são entendidos como "as formas pelas quais as professoras sentem, percebem, agem e expressam seus sentimentos em relação às crianças, famílias e ao trabalho que desenvolvem" (CARVALHO, 2014, p. 236) na creche. Esse entendimento é importante para que seja reconhecido o "denso conteúdo afetivo" (FERNANDES, 2011) da docência com bebês (permeado por sentimentos variados), a "contingência dos afetos" (ILLOUZ, 2011), bem como esclarecido que os afetos das professoras "não ocorrem de modo natural, não nascem de seus corações e nem de suas entranhas" (ABRAMOWSKI, 2010), mas são produzidos e significados culturalmente (REZENDE; COELHO, 2010). Como se pode depreender, "os afetos, em todas as suas variantes, não são puros, naturais, espontâneos, instintivos, universais, eternos nem imutáveis" (CARVALHO, 2014, p. 236), e sim históricos, ambivalentes, construídos e aprendidos pela professora no contexto de sua docência, como poderá ser observado na transcrição das narrativas apresentadas a seguir:

P014: O afeto está sempre presente em nosso trabalho com os bebês na creche, pois exercemos intensamente práticas de cuidado. Mas não é afeto somente no sentido de sentimento de carinho, respeito e afeição pelas crianças. Afinal, somos humanas, e não máquinas. Por isso, refiro-me também ao afeto no sentido de ser afetado, de afetar os outros, como nós discutimos com as colegas no grupo focal no encontro passado. Somos afetadas e afetamos diariamente os bebês, os nossos pares, as famílias e as demais crianças na escola. Confesso que trabalhar em turno integral com o B1 é viver um turbilhão de sentimentos, que nem sempre são aceitos e respeitados pelas colegas e direção da creche. Na verdade, ninguém se preocupa com o que nos afeta, com o modo como somos afetadas. A preocupação centra-se sempre em como nós devemos afetar os outros. Em resumo, eu posso dizer que a alegria, a tristeza, a impotência, a calma, o cansaço, a euforia e a realização são elementos com os quais nós, professoras de berçário, temos que aprender a lidar diariamente.

4 No intuito de garantir o anonimato das participantes da pesquisa, as professoras serão nomeadas pela letra $\mathrm{P}$ (professora), seguida de um número (01-20), correspondente àquele atribuído a cada uma delas.

RIAEE - Revista Ibero-Americana de Estudos em Educação, Araraquara, v. 14, n. 1, p. 188-207, jan./mar., 2019. E-ISSN: $1982-5587$. 
P08: Eu concordo com o relato da colega sobre a concepção cultural de afeto, porém gostaria de acrescentar que as relações de cuidado com os bebês são centrais em nossas ações como professoras. A nossa prática pedagógica é permeada pelo cuidado, e isso é muito visível para todas as pessoas com as quais lidamos diariamente. A mãe que deixa o seu bebê na creche certamente espera que ele seja bem cuidado, tendo todas as suas necessidades atendidas. Desse modo, é natural que as nossas colegas entendam os afetos docentes exclusivamente no âmbito dos cuidados que temos com os bebês. Afinal, afeto e relações de cuidado são aspectos constituintes de nossa docência. Por outro lado, o que me espanta é o fato de sermos muitas vezes avaliadas, criticadas e menosprezadas profissionalmente por nossas próprias colegas, professoras das crianças maiores, pelo fato de passarmos muito tempo cuidando dos bebês. Enfim, somos cobradas pelos nossos pares para exercermos a "correta medida dos afetos" nas práticas de cuidado com os bebês, já que não devemos ser confundidas com mães ou simples cuidadoras.

(Grupo Focal - $5^{\circ}$ encontro)

A leitura da primeira narrativa evidencia que a professora não significa o afeto somente em um sentido restrito, traduzido comumente pelos modos como se afeta (ou se deve afetar) os outros. Em suas palavras, ela descreve o afeto como potência que movimenta as relações, colocando em xeque perspectivas que reduzem os sentimentos ao plano privado das emoções.

O dito pela professora destaca a tensão entre o "imperativo do afeto" (CARVALHO, 2014) e a intensa regulação sobre os sentimentos considerados "politicamente incorretos" (ABRAMOWSKI, 2010), o "denso conteúdo afetivo" (FERNANDES, 2011) da docência na creche e a necessidade de atenção e reconhecimento em relação à complexidade envolvida no árduo trabalho de ser professora de bebês. Alegria, tristeza, impotência, calma, cansaço, euforia e realização são citados pela professora como parte de uma "gramática das emoções" (REZENDE; COELHO, 2010; REZENDE, 2012) com as quais ela precisa aprender a lidar no exercício diário de sua profissão.

Nesse panorama, os afetos expressos nas relações de cuidado das professoras com os bebês adquirem centralidade, conforme destacado com maior ênfase na segunda narrativa apresentada. Isso porque os afetos possuem um significado moral, o qual é potencializado durante as práticas de cuidado com os bebês (TRONTO, 1997). É por meio da demonstração da "medida correta dos afetos" (devendo ser evitados os excessos) no exercício do cuidado com os bebês que as docentes são "avaliadas, criticadas e até mesmo menosprezadas" pelos seus pares, quando ultrapassam os limites do que convencionalmente é instituído como sendo a expressão adequada dos afetos. Tais considerações são importantes para que se possam 
evidenciar as relações entre os afetos docentes e o significado moral das práticas de cuidado na creche.

Desse modo, a partir do entendimento de que as relações de cuidado são constituídas por "uma atenção pessoal contínua e intensa que melhora o bem-estar de seus destinatários" (ZELIZER, 2011, p. 138), de que o ato de cuidar implica compromisso e de que, além disso, possui significado moral de acordo com o seu objeto (TRONTO, 1997), é imprescindível esclarecer os sentidos generificados atribuídos à palavra "cuidado". A esse respeito, Tronto (1997) apresenta uma interessante e produtiva distinção entre as expressões "cuidado com" e "cuidado de".

O "cuidado com", segundo a referida autora, corresponde a um modo geral de compromisso, pois se refere a objetos menos concretos. Para a autora, o "cuidado de" é significado moralmente no contexto social (e também se pode dizer que no âmbito da creche enquanto instituição), porque implica a existência de um objeto específico para o qual o sujeito dirige sua atenção (TRONTO, 1997). Nessa perspectiva, a crítica de Tronto (1997) centra-se no fato de que, geralmente, o "cuidado com" é atribuído aos homens e o "cuidado de" é dispensado às mulheres (por ser considerado um trabalho de menor prestígio e sem valor social) e a profissionais atuantes em áreas da docência, assistência social, enfermagem, etc., ou seja, profissões diretamente implicadas no cuidado do outro.

No quadro da pesquisa, conforme pode ser acompanhado nas narrativas apresentadas, as docentes estão intensamente envolvidas com o "cuidado dos" bebês (mesmo que este tenha um cunho educativo), já que atuam como apoio substituto às famílias quanto ao atendimento das necessidades das crianças. Tal aspecto torna as relações de cuidado exercidas pelas docentes na creche passíveis de significação moral (CARVALHO, 2014) e regulação contínua pelas colegas das etapas subsequentes. Pelo fato de o cuidado com os bebês ser considerado (de modo naturalizado) uma ação tipicamente feminina, proveniente do âmbito doméstico e, portanto, sem reconhecimento público e político (MARTINS, 2014), sua exacerbação por meio da expressão de afetos que ultrapassem a "correta medida" é refutada pelas professoras das crianças maiores. Isso significa que "no campo educativo [especialmente no contexto da creche] o afetivo está por momentos sobrevalorizado e por outros, questionado e desqualificado" (ABRAMOWSKI, 2010, p. 82), pois o espaço da suspeita se localiza no argumento da desprofissionalização.

Nesse sentido, como lembra Fernandes (2011, p. 11), “o desafio hercúleo que atravessa décadas [ainda] se mantém: mostrar o conteúdo do que se chama de doméstico, 
passar do invisível para o visível, fazer aparecer o trabalho escondido". Isto é, no âmbito da discussão sendo desenvolvida, "é preciso valorizar a experiência feminina, desconstruindo elementos de subordinação patriarcal, sem jogar fora o saber que é fruto dos modos históricos de pensar-sentir-fazer, próprios das mulheres" (GUIMARÃES, 2011, p. 49).

Portanto, com base no panorama descrito, cabe ainda ressaltar que as professoras atuantes na creche estão inseridas em um espaço de vida coletiva que exige um envolvimento intenso com os bebês e com as famílias, além da manutenção de atividades concomitantes (SCHMITT, 2014), partes do ofício da docência, como o planejamento, a documentação do trabalho, as reuniões, o atendimento às famílias, entre outras inúmeras tarefas. Sem dúvida, as professoras do berçário vivenciam um "turbilhão de sentimentos" no cotidiano profissional nem sempre aceitos e reconhecidos como elementos constitutivos da prática docente, pois, como aponta Abramowski (2010, p. 63), "a professora não tem via livre para sentir qualquer coisa".

Por essa razão, a professora é incitada a regular seus sentimentos "a partir de um processo de disciplinamento e correlato aprendizado de autogoverno, que se inicia na família e se estende pela escolarização e pelo convívio social nas instituições" (CARVALHO, 2014, p. 237) educacionais em que atua. Trata-se do contínuo aprendizado de controle dos "afetos (considerados) politicamente incorretos" (ABRAMOWSKI, 2010) no exercício da docência, sentimentos que as professoras aprendem não ser conveniente sentir ou expressar e os quais, portanto, devem aprender a "controlar, medir, dominar e metabolizar" (ABRAMOWSKI, 2010, p. 61) para serem reconhecidas profissionalmente pelos seus pares. Tal discussão será o enfoque analítico da próxima seção.

\section{$O$ afeto docente (como imperativo), o cuidado com os bebês e a regulação das emoções}

P20: A docência no berçário é bem cansativa, porém existe uma exigência implícita de que temos que estar sempre alegres. Qualquer demonstração de cansaço ou falta de paciência, a coordenadora e as colegas das outras turmas já criticam, pois consideram que o nosso mau humor pode interferir negativamente nos modos como cuidamos dos bebês. Isso é totalmente arbitrário e sem sentido. Elas esquecem que o trabalho com as crianças maiores é menos cansativo. Sem falar no tranquilo trabalho da coordenação, que consiste em não fazer nada o dia inteiro.

Pesquisador: E qual é o motivo da crítica?

P20: Elas acham que a gente deve estar sempre bem-humorada, porque temos jeito para trabalhar com bebês. Acham que se abaixar, trocar fraldas, pegar bebê pesado no colo é algo muito simples. Trabalhar em turno integral com BI é extremamente desgastante. Quando chega o final da 
semana, geralmente eu vou ficando mais cansada, e os sorrisos e bom humor começam a diminuir, porém isso não afeta em nada o meu cuidado com os bebês. Eu perco a paciência somente com os adultos, pois tenho consciência de que devo manter o controle e jamais perder a calma com os bebês. Por essa razão, afirmo tranquilamente que a expressão dos meus sentimentos jamais interfere negativamente nas relações de cuidado que estabeleço com os bebês do meu grupo.

P07: Na creche em que eu trabalho, também existe essa política de não poder expressar afetos considerados incorretos, como cansaço, mau humor, tristeza, angústia, etc. Além disso, também temos que ouvir de modo reiterado que temos jeito para cuidar bebês. Isso porque o jeito com os bebês é visto como uma espécie de dom, com o qual as professoras de berçário nascem dotadas. Todos os anos, por exemplo, ninguém quer assumir o B1, e a justificativa é a de que elas não têm jeito para cuidar das crianças. Por outro lado, se eu não estiver sempre sorridente, a coordenadora já pergunta: "- Professora, o que houve? Se você continuar com cara feia, os bebês irão ficar tristes e chorar. Não esqueça que ainda temos bebês em período de adaptação. Garanto que, com os seus filhos, você não fica mal-humorada”. O que a coordenadora esquece é que quem realiza a adaptação com os bebês diariamente sou eu. Parece que trabalhar com bebês é uma tarefa que não exige esforço. Para a minha coordenadora, basta que eu mantenha o sorriso no rosto e tudo será resolvido.

Pesquisador: E vocês vivenciam alguma situação semelhante no cotidiano da creche?

P15: Ouvindo as colegas, parece que estou vendo as professoras da minha escola e coordenadora. Tudo é muito semelhante, até essa história de que tenho jeito para lidar com os bebês. Só muda o endereço, parece que elas estão falando da minha escola.

P04: As situações relatadas são típicas na creche. Como professoras de berçários, somos convocadas a sermos sempre afetivas e adoráveis com todas as pessoas. Acho que isso tem a ver também com a relação direta que algumas pessoas, baseadas no senso comum, estabelecem com a maternidade. Afinal, a mãe não tem tempo para ficar cansada. A mãe tem que estar sempre alegre e disposta para o trabalho, por mais pesado que seja. A creche, na verdade, reproduz o retrato de uma sociedade machista e patriarcal.

P18: Nossa, eu concordo plenamente com a colega. Vivencio isso diariamente. É muito complicado, ninguém se coloca no lugar da gente. Não basta dizer que temos jeito, pois isso é uma ficção produzida para cercear nossos direitos enquanto professoras. $E$ preciso reconhecer o nosso trabalho. Na semana passada, uma colega teve a capacidade de dizer, no intervalo do almoço, para eu usar um corretivo em minhas olheiras, pois a minha aparência era de uma pessoa muito cansada. Eu simplesmente disse que não era apenas a aparência, mas que eu estava extremamente cansada.

P10: Olha, o que posso dizer é que acho tudo isso muito injusto e desgastante. Apoio, nenhuma colega oferece. Até mesmo as professoras volantes fogem da sala do berçário. Diariamente, eu vivencio uma cobrança intensa para ser amorosa, sorridente, afetiva, alegre e bem-humorada porque sou professora de bebês. Infelizmente, o fardo de ser uma professora perfeita vem junto com a tarefa de atuar com os pequenos. (Grupo Focal $5^{\circ}$ encontro) 
A presença de um "gênero do cuidado" (STRATHERN, 2006) e a operação de uma "gramática das emoções" (REZENDE, 2012) reguladora dos modos de expressão das professoras são a tônica da problemática discutida pelas participantes da pesquisa. Nessa perspectiva, “o imperativo do afeto na prática docente" (CARVALHO, 2014) configura-se como o mote de discussão, pois, como salienta Abramowski (2010, p. 33), "por mais que os sentimentos pareçam familiares, não se deve perder de vista que seu sentido está condicionado e definido por horizontes sociais, culturais, conceituais e valorativos". Desse modo, a leitura das narrativas apresentadas evidencia claramente a percepção das professoras sobre as exigências relativas aos modos como devem expressar seus sentimentos, o reconhecimento da posição de sujeito subalterno que ocupam enquanto profissionais no âmbito institucional e a urgente necessidade de se deslocarem dessa posição a partir da problematização das "imagens de docência" (CARVALHO; RADOMSKI, 2017) historicamente promovidas e naturalizadas no âmbito laboral da creche.

No contexto da pesquisa, ser alegre, bem-humorada, afetiva e adorável são exigências institucionais a serem alcançadas pela professora que atua com bebês. $\mathrm{O}$ bom humor, a alegria, o amor e o carinho são considerados sentimentos que devem andar lado a lado com as obrigações (REZENDE; COELHO, 2010) docentes.

Nesse sentido, é possível afirmar que "existem prazeres permitidos, formas corretas de expressar e maneiras apropriadas de sentir" (ABRAMOWSKI, 2010, p. 57) a serem aprendidos pelas professoras na labuta diária. Por outro lado, "existem prazeres proibidos, modos não agradáveis de manifestar os sentimentos e emoções inomináveis" (ABRAMOWSKI, 2010, p. 57), a serem banidos pelas docentes.

Ora, é sempre bom lembrar que o imperativo do afeto demanda, educa e incita a construção da imagem modelar de uma professora de creche "naturalmente afetiva, materna, carinhosa, paciente, dedicada, perspicaz, dinâmica e educadora nata" (CARVALHO, 2014, p. 242), cujo trabalho é visto como um desdobramento das tarefas domésticas de organização do lar, cuidado e educação dos bebês. Por esse ponto de vista, o cuidar é considerado um aspecto de desprestígio nas práticas das professoras que atuam com bebês nas creches (MARTINS, 2014).

Nas discussões sendo desenvolvidas, outro aspecto importante merecedor de destaque na análise das narrativas apresentadas é a recorrência de um argumento de cunho moral: as colegas das professoras participantes da pesquisa afirmam que estas têm um "jeito" (especial) para lidar com os bebês, uma espécie de "dom" concedido somente às professoras do 
berçário. A esse respeito, Fernandes (2011, p. 39) declara que "falar do jeito de alguém cuidar uma criança, é falar da moral de outrem, é estabelecer um juízo".

Conforme a referida autora, "o jeito de falar com a criança, o jeito de educar, o jeito de vestir, a forma de dar a comida, os horários de dormir, podem tornar-se motivo para profundas dissidências" (FERNANDES, 2011, p. 46). Assim, enquanto aspecto emergente da ordem da moralidade (TRONTO, 1997), "ter jeito para cuidar os bebês" configura-se como um critério para a expressão da avaliação sobre os modos como as professoras participantes da pesquisa exprimem "o amor, o carinho, o toque, o zelo, a educação, a imposição de limites, a alimentação, o respeito, a vigília dos horários da criança, os olhares, a impostação da voz" (FERNANDES, 2011, p. 39).

Nessa lógica, o "jeito de cuidar" das professoras é significado como um qualificador de relações, cujo efeito é a sobrecarga de trabalho, a falta de reconhecimento das ações desenvolvidas e a imposição de que a alegria e o bom humor sejam permanentes, não importando o cansaço e o "turbilhão" de sentimentos vivenciados em um mesmo dia. Ou seja, "para se cuidar de uma criança é preciso ter jeito, é preciso possuir esta qualidade retratada como inata" (FERNANDES, 2011, p. 39).

A partir de tais considerações, cabe salientar que a crítica ao modo como é significado o trabalho desenvolvido pelas professoras participantes da pesquisa no contexto da creche de forma alguma recai sobre a importância do cuidado que estas devem ter com os bebês. Certamente, o cuidado é uma função fundamental da ação educativa, "na perspectiva de atenção ao outro, de integração e de concretização da creche como espaço de vida" (GUIMARÃES, 2011, p. 54).

O foco da crítica é às demandas geradas pelo imperativo do afeto (CARVALHO, 2014), o qual regula a expressão de sentimentos (considerados) politicamente incorretos (ABRAMOWSKI, 2010), contribuindo para a desqualificação, precarização e falta de reconhecimento do trabalho desenvolvido pela professora que atua no berçário. Não se deve esquecer que a creche é um espaço social constituído através das relações estabelecidas em seu contexto, ou seja, "um lugar repleto de subjetividades e significações que ganham contornos na medida em que se vivenciam experiências com e entre seres humanos" (GONÇALVES, 2014, p. 97).

Por fim, é necessário destacar que a docência no berçário não diz respeito a ter ou não “jeito” com bebês, mas ao exercício de uma profissão que demanda qualificação, respeito e reconhecimento pela sua potência e singularidade. Para tanto, é preciso discutir o "estatuto 
teórico do cuidar, como caminho para construção de uma nova visão acerca das profissionais do cuidado nas creches, compreendendo que nelas se faz educação que se alimenta e se reinventa no cuidar do outro" (GUIMARÃES, 2011, p. 53).

Prosseguindo a discussão, será focalizada, na próxima seção, a regulação dos afetos docentes e suas implicações nas relações de cuidado com os bebês.

\section{A "correta medida" dos afetos nas relações de cuidado com os bebês}

P08: Fico muito incomodada com a falta de reconhecimento do trabalho que desenvolvo na creche. As minhas colegas enxergam sempre a professora de berçário como uma profissional inferior. Eu fiz graduação, especialização e, se estou atuando na docência com bebês, é porque escolhi esse caminho como profissão. Eu observo diariamente um grande paradoxo em relação ao modo como são tratadas as professoras de berçário. Somos cobradas para sermos afetivas em nossa prática docente, mas demonstrar afeto em excesso pelos bebês se torna uma razão de desprestígio profissional.

Pesquisador: Como assim? O que é afeto em excesso? Você poderia explicar melhor?

P12: Por exemplo, eu não deixo nenhum bebê do meu grupo chorar. Eu dou atenção, pego no colo, afago, converso, canto alguma música; enfim, faço de tudo para o bebê ficar calmo. Por outro lado, escuto muitas críticas em meu trabalho. Algumas colegas dizem que o meu cuidado não é pedagógico, pois sou muito afetiva. Elas dizem ainda que eu sou apegada aos bebês e que isso desqualifica a minha ação. Vocês conseguem entender? Eu confesso que não consigo. Temos que ser afetivas, mas não muito. $O$ cuidado deve ser pedagógico. É tanta asneira que eu acabo fazendo ouvido de mercador.

P18: Na docência no berçário é evidente que não temos o mesmo prestígio profissional das professoras que atuam com as crianças maiores. Eu fico extremamente incomodada quando ouço alguma colega dizendo: "-Olha as mãezinhas. Vocês gostam de brincar de boneca. Se fosse para limpar bunda de bebê, eu ficaria em casa cuidando dos meus". É uma falta de respeito. Existe um menosprezo em relação ao nosso trabalho devido à presença marcante de práticas de cuidado que se aproximam das atividades domésticas. Eu tenho consciência do meu papel profissional e conhecimento de como deve ser a minha atuação docente, porém, para as colegas, o fato de estar próxima aos bebês, a partir de uma relação afetiva muito intensa, desencadeada pelo cuidado que tenho com os pequenos, gera inúmeras críticas, sendo que a principal crítica é a de que me apego aos bebês como se fossem meus.

P03: Eu ouço de modo recorrente: “- É muito colinho e apego. Você só fica dando colinho, trocando fraldas e oferecendo comida o tempo todo. Deixa essas crianças chorarem um pouco. Parece que você não sabe que temos rotina. Cadê as atividades? Como é que você irá organizar os portfólios no final do trimestre?". O mais assustador é que não é só a coordenadora que fala isso; as minhas colegas também reiteram esses conselhos diariamente. Parece que elas não sabem que cuidar e educar são dois aspectos 
indissociáveis. Além disso, o que é considerado atividade em uma turma de bebês?

P16: Os relatos compartilhados são bons exemplos do que passamos cotidianamente. Isso é o que eu chamo de paradoxo. O afeto pelo qual somos cobradas pelos nossos pares tem se tornado a razão do nosso desprestígio profissional, ou melhor, do lugar profissional subalterno que temos ocupado no contexto da Educação Infantil. Não ser afetiva é um problema, mas demonstrar o que nossas colegas de profissão definem como afeto em excesso é motivo de falta e reconhecimento profissional. O que elas definem como apego é a proximidade que estabelecemos com os bebês. Isso porque nossas colegas consideram que a verdadeira professora é aquela que ensina algo pautado em um currículo disciplinar para as crianças.

P19: Na verdade, o que eu percebo é uma falta de reconhecimento das minhas colegas de trabalho em relação às práticas que envolvem o cuidado. $O$ cuidado é relacionado diretamente com as tarefas domésticas maternas; por essa razão, acredito que ele seja totalmente desvalorizado no que diz respeito ao status profissional dentro da creche.

(Grupo Focal - $5^{\circ}$ encontro)

A leitura das narrativas transcritas evidencia a marcante dissidência entre as professoras participantes da pesquisa e suas respectivas colegas de trabalho no que diz respeito aos modos como devem ser expressos os afetos no exercício da docência com os bebês. Nessa perspectiva, "pegar muito os bebês no colo e, consequentemente, desenvolver poucas atividades" é visto como o exercício de um “cuidado não pedagógico", o qual deve ser banido pelo fato de estar muito próximo das atividades desenvolvidas pelas mães das crianças.

Tal fato evidencia que as atividades maternas são consideradas um "assunto pessoal" (ZELIZER, 2011) e que, portanto, não devem ter qualquer relação com a docência. Essa questão se encontra presente no argumento de Zelizer (2011), quando discute a "noção do que é considerado pessoal nos processos de intimidade", ou seja, os bebês, embora tenham seus cuidados compartilhados com as docentes na instituição, são considerados um "assunto pessoal", de âmbito privado familiar. Desse modo, "apegar-se" aos bebês durante o trabalho cotidiano é considerado uma ação indevida, pelo fato de "borrar" as fronteiras entre o âmbito pessoal e o profissional.

Partindo desses apontamentos, dois aspectos devem ser destacados nas análises: 1) "o contágio do doméstico" nas relações de cuidado, entendido como a tensão entre os saberes emergentes do lar, a maternagem e a experiência profissional docente (GUIMARÃES, 2011, p. 2) o "didatismo pedagógico", pautado na concepção de que a ação docente com bebês deve ser promotora da realização de atividades que sejam expressas em produções concretas (CARVALHO; RADOMSKI, 2017) para a composição de portfólios a serem entregues aos 
pais como evidências do trabalho realizado. Por esse motivo, no contexto da pesquisa, dar atenção "em excesso" aos bebês é visto de modo pejorativo pelas professoras dos níveis subsequentes ao berçário, nomeando essas ações como sendo da ordem da maternidade, do ser "mãezinha" ou, ainda, do universo lúdico, quando se referem ao "brincar de boneca".

Este é o paradoxo vivenciado pelas professoras participantes da pesquisa: o desafio de encontrar a "correta medida dos afetos", isto é, ser afetiva com os bebês sem demonstrar excessos. Esse argumento é ratificado na narrativa da docente quando afirma que: "o afeto pelo qual somos cobradas pelos nossos pares tem se tornado a razão do nosso desprestígio profissional, ou melhor, do lugar profissional subalterno que temos ocupado" (P16). Por essa razão, no âmbito das práticas cotidianas desenvolvidas nas creches, ainda é importante discutir e aprofundar o que significa o caráter cultural dos afetos (ABRAMOWSKI, 2010; CARVALHO, 2014).

Assim, a partir das considerações apresentadas, cabe reiterar que a disputa em torno do entendimento do que é considerado o modo adequado de expressar afeto durante as práticas de cuidado com os bebês faz parte de uma "gramática das emoções" (REZENDE, 2012) que define como devem ser expressos os afetos na prática desenvolvida pelas professoras. Isso porque, no contexto profissional em que atuam as participantes da pesquisa, o "excesso de afeto" - entendido como pegar os bebês no colo constantemente, trocar fraldas muitas vezes, ofertar alimentos além dos horários previstos, não deixar os bebês chorando - transforma-se em "apego" (FERNANDES, 2011). Nessa lógica, o apego é significado como um "sentimento da ordem dos excessos" (FERNANDES, 2011), a se evitar, por ser considerado um aspecto exclusivo do âmbito familiar.

Como se pode observar, para as professoras que não atuam no berçário, o apego aos bebês é considerado um sentimento que rompe o tênue limite entre o doméstico e o profissional, corroborando a desqualificação da ação docente na creche. Diante de questões como essa, Fernandes (2011, p. 46) esclarece que o apego é considerado ruim "porque introduz um sentimento que extrapola a relação previamente estabelecida entre pessoas unidas na chave da amizade e do parentesco".

Embora exista um imperativo do afeto (CARVALHO, 2014) no cotidiano institucional, também é evidente a presença de um "mandato pedagógico" (ABRAMOWSKI, 2010), o qual sinaliza não ser permitido se apegar aos bebês. Isso equivale a dizer que as professoras, no exercício de sua tarefa, devem aprender a sentir e a expressar seus afetos de acordo com os modos de regulação institucional, ou seja, "existe um como e quando ser 
afetiva que disciplina as docentes a formatarem seus afetos e a recorrerem a certas emoções somente em determinados momentos" (ABRAMOWSKI, 2010, p. 54).

Feitas essas considerações, é interessante ainda destacar a evidente oposição entre cuidado e educação, reportada pelas professoras em suas narrativas, quando se referem às críticas recebidas pelos seus pares em relação à falta de atividades "pedagógicas" com os bebês. Isso ocorre porque, para legitimar a profissão, as professoras das turmas de crianças maiores expressam, em suas recomendações às docentes do berçário, "a obrigação de realizar atividades que se assemelhem ao ensino fundamental, tendo em vista ensinar algo concreto com resultados palpáveis e possíveis de serem avaliados" (GONÇALVES, 2014, p. 78). Dessa forma, é possível depreender a existência da compreensão da necessidade de haver a produção de algo pelos bebês para que o trabalho desenvolvido seja considerado educativo.

Nessa direção, é perceptível a onipresença de um “didatismo pedagógico" (CARVALHO; RADOMSKI, 2017) que impede o entendimento de que o trabalho docente com bebês seja uma "ação educativa pedagógica em todas as relações estabelecidas nesse contexto, sejam as que envolvem a ação direta da profissional com as crianças, sejam as ações em volta da organização do tempo e espaço" (SCHIMITT, 2014, p. 48), materiais e relações que os bebês estabelecem entre si, com os outros e com o mundo.

$\mathrm{Na}$ próxima seção, serão apresentadas as considerações finais das discussões empreendidas no decorrer do artigo.

\section{Considerações finais}

Conforme lembra Abramowski (2010, p. 115), “os afetos docentes são uma marca constitutiva do oficio do professor". Isso porque, "longe de serem pré-sociais ou préculturais" (ILLOUZ, 2011, p. 9), os afetos são produzidos no contexto das relações sociais estabelecidas entre as pessoas. Em outras palavras, pode-se dizer que a docência, pelo fato de ser pautada "nas relações entre pessoas, é permeada pelos afetos, pela simpatia e antipatia que acompanha as relações" (OSTETTO, 2008, p. 136).

Desse modo, a partir das análises das narrativas apresentadas no decorrer do artigo, pode-se inferir que os significados dos afetos docentes na creche são decorrentes de construções culturais" (REZENDE; COELHO, 2010), das quais emergem mandatos pedagógicos afetivos (ABRAMOWSKI, 2010) que incidem diretamente nos modos de constituição profissional das professoras de bebês. Assim, deve-se compreender que "as 
relações de cuidado no contexto da creche se mostram como fonte inesgotável de emoções" (FERNANDES, 2011, p. 11), dado que existe, no campo da prática pedagógica, "muito mais do que domínio teórico, competência técnica e compromisso político, pois se encontra em jogo a subjetividade dos sujeitos implicados" (OSTETTO, 2008, p. 128). Ou seja, "as formas de tratar as crianças e, portanto, de cuidar, dizem muito sobre as concepções que se têm sobre estas" (FERNANDES, 2011, p. 132).

Nesse sentido, por meio das análises, também foi possível perceber o "denso conteúdo afetivo" (FERNANDES, 2011) presente nas relações de cuidado estabelecidas entre as professoras e os bebês, assim como o campo de disputas em torno dos modos de significação dos afetos docentes (CARVALHO, 2014) no cotidiano institucional. Dessa maneira, ter “jeito" (FERNANDES, 2011) para cuidar os bebês - entender suas necessidades - é visto na creche pelos pares das professoras participantes da pesquisa como um critério imprescindível para atuação no berçário.

No entanto, como foi evidenciado nas narrativas, tal critério limita a expressão das emoções das docentes, sobrecarregando-as laboralmente. As professoras, por serem consideradas naturalmente hábeis para trabalhar com os bebês, devem estar sempre dispostas, alegres e confortáveis durante sua árdua rotina, sem ao menos terem seu trabalho reconhecido. Esse entendimento corrobora a visão equivocada e recorrente de que "as emoções são fenômenos universalmente compartilhados, posto que fruto de uma unidade biológica e psicológica do ser humano" (REZENDE; COELHO, 2010, p. 33).

Por conseguinte, demonstrar "apego" (FERNANDES, 2011) pelos bebês - "excesso" de atenção nas práticas de cuidado - é considerado pelas colegas das participantes da pesquisa como algo a ser banido das ações diárias, pois, indefectivelmente, aproxima as professoras do trabalho doméstico exercido pelas mães das crianças. A esse respeito, existe a preocupação de que as professoras de bebês não "descaracterizem" a ação profissional no berçário, isto é, não se "contagiem pelo doméstico" (GUIMARÃES, 2011).

Como é possível perceber, os afetos - expressos nos cuidados das professoras com os bebês - possuem uma importância cardinal nos modos de organização da creche, já que, além de serem permanentemente regulados (ABRAMOWSKI, 2010), expressam hierarquias e distinções entre as docentes. Em tal perspectiva, é possível afirmar que a reflexão sobre as relações sociais no âmbito da creche, além de serem importantes para que o professor "aprenda a ver além do aparente e a construir um olhar implicado" (OSTETTO, 2008, p. 129) sobre as práticas pedagógicas desenvolvidas com os bebês, "é também matéria-prima para que 
o mesmo possa compreender os contornos da própria docência, de forma situada e atenta as especificidades que contornam aqueles a quem a ação é dirigida" (SCHMITT, 2014, p. 259).

Por fim, as contribuições da pesquisa descrita no presente artigo podem auxiliar para tensionar e problematizar as questões relacionadas aos afetos docentes e às relações de cuidado na creche. Afinal, em termos éticos, políticos e pedagógicos, cabe o desafio de construir outras narrativas sobre os afetos, colaborando, desse modo, para o entendimento de que "a ação docente, fundada na relação com os outros, não apenas interfere na constituição dos bebês, mas também é interferida pelas relações que a envolvem" (SCHMITT, 2014, p. 259). Nesse sentido, "ser profissional da educação significa experimentar sentimentos" (OSTETTO, 2008, p. 136). Isso implica enfrentar o desafio de "retirar os afetos docentes de uma zona escondida e estritamente singular, para situá-los em um plano coletivo, social, cultural e histórico" (ABRAMOWSKI, 2010, p. 167) do qual fazem parte os professores envolvidos com a educação dos recém-chegados ao mundo.

\section{REFERÊNCIAS}

ABRAMOWSKI, Ana. Maneras de querer: los afectos docentes en las relaciones pedagógicas. Buenos Aires: Paidós, 2010.

BARBOUR, Rosaline. Grupos Focais. Porto Alegre: Artmed, 2009.

CARVALHO, Rodrigo Saballa. O imperativo do afeto na Educação Infantil: a ordem do discurso de pedagogas em formação. Educação e Pesquisa, São Paulo, v. 40, n. 1, p. 231 246, jan./mar. 2014. Disponível em: http://www.scielo.br/pdf/ep/v40n1/aop1291.pdf. Acesso em: 20 maio 2017.

CARVALHO, Rodrigo Saballa; RADOMSKI, Lidianne Laizi. Imagens da docência com bebês: problematizando narrativas de professoras de creche. Série-Estudos, Campo Grande, MS, v. 22, n. 44, p. 41-59, jan./abr. 2017. Disponível em: http://www.serieestudos.ucdb.br/index.php/serie-estudos/article/view/1015. Acesso em: 10 maio 2017.

CASTRO, Joselma Salazar. A docência na Educação Infantil como ato pedagógico. 2016. 343f. Tese (Doutorado em Educação) - Universidade Federal de Santa Catarina, Florianópolis, SC, 2016.

FERNANDES, Camila. "Ficar com": parentesco, criança e gênero no cotidiano. 2011. 143f. Dissertação (Mestrado em Antropologia) - Universidade Federal Fluminense, Niterói, RJ, 2011.

FLICK, Uwe. Introdução à pesquisa qualitativa. Porto Alegre: Artmed, 2009. 
GONÇALVES, Fernanda. A educação de bebês e crianças pequenas no contexto da creche: uma análise da produção científica recente. 2014. 202f. Dissertação (Mestrado em Educação) - Universidade Federal de Santa Catarina, Florianópolis, SC, 2014.

GONDIM, Sônia Maria Guedes. Grupos focais como técnica de investigação qualitativa: desafios metodológicos. Paidéia, Ribeirão Preto, SP, v. 12, n. 24, p. 149-161, mar./abr. 2003. Disponível em: http://www.scielo.br/pdf/paideia/v12n24/04.pdf. Acesso em: 12 jun. 2017.

GUIMARÃES, Daniela. Relações entre bebês e adultos na creche: o cuidado como ética. São Paulo: Cortez, 2009.

ILLOUZ, Eva. O amor nos tempos do capitalismo. Rio de Janeiro: Zahar, 2011.

LEOVORLINO, Solange Abrocesi; PELICIONI, Maria Cecília Focesi. A utilização do grupo focal como metodologia qualitativa na promoção da saúde. Revista da Escola de Enfermagem, São Paulo, v. 35, n. 2, p. 115-121, jun. 2001. Disponível em: http://www.revistas.usp.br/reeusp/article/view/41220/44772. Acesso em: 15 abr. 2017.

LOURO, Guacira Lopes (Org.). O corpo educado: pedagogias da sexualidade. Belo Horizonte: Autêntica, 1999.

MARTINS, Ana Cláudia Ferreira. A construção das identidades profissionais das professoras de bebês. 2014. 134f. Dissertação (Mestrado em Estudos da Criança) - Instituto de Educação, Universidade do Minho, Portugal, 2014.

MEYER, Dagmar. Gênero e Educação: teoria e política. In: LOURO, Guacira Lopes; NECKEL, Jane Felipe; GOELLNER, Silvana Vilodre. Corpo, gênero e sexualidade: um debate contemporâneo. Petrópolis, RJ: Vozes, 2003. p. 9-27.

OSTETTO, Luciana Esmeralda. O estágio curricular no processo de tornar-se professor. In: OSTETTO, Luciana Esmeralda (Org.). Educação Infantil: saberes e fazeres da formação de professores. Campinas, SP: Papirus, 2008. p. 127-138.

REZENDE, Claudia Barcellos. Emoção, corpo e moral em grupos de gestante. Revista Brasileira de Sociologia da Emoção, João Pessoa, PB, v. 11, n. 33, p. 830-849, dez. 2012. Disponível em: http://www.cchla.ufpb.br/rbse/ClaudiaRezDos.pdf. Acesso em: 15 abr. 2017.

REZENDE, Claudia Barcellos; COELHO, Maria Cláudia. Antropologia das emoções. Rio de Janeiro: FGV, 2010.

SCHMITT, Rosinete Valdeci. As relações sociais entre professoras, bebês e crianças pequenas: contornos da ação docente. 2014. 282f. Tese (Doutorado em Educação) Universidade Federal de Santa Catarina, Florianópolis, SC, 2014.

STRATHERN, Marilyn. O Gênero da Dádiva: problemas com as mulheres e problemas com a sociedade na Melanésia. Campinas, SP: Unicamp, 2006. 
TRONTO, Joan. Mulheres e cuidados: o que as feministas podem aprender sobre a moralidade a partir disso? In: BORDO, Susan; JAGUAR, Alisson. (Orgs.). Gênero, corpo, conhecimento. Rio de Janeiro: Rosa dos Ventos, 1997. p. 186 -213.

ZELIZER, Viviana A. A negociação da intimidade. São Paulo: Editora Vozes, 2011.

\section{Como referenciar este artigo}

CARVALHO, R. S. de. Afetos docentes e relações de cuidado na creche: narrativas de professoras em discussão. Revista Ibero-Americana de Estudos em Educação, Araraquara, v. $14, \quad$ n. 1 , p. 188-207, jan./mar., 2019. E-ISSN: 1982-5587. DOI: 10.21723/riaee.v14i1.10239

Submissão: 07/08/2017

Revisões requeridas: 10/01/2018

Aprovação final: 15/06/2018 